\title{
Maternal metabolic abnormalities in twin-to-twin transfusion syndrome at mid-pregnancy
}

\author{
Julian E De Lia ${ }^{1}$, Randall S KuhImann ${ }^{2}$ and Maurice G Emery ${ }^{3}$ \\ ${ }^{1}$ Department of Obstetrics and Gynecology, University of Illinois, Chicago, Illinois \\ ${ }^{2}$ Department of Obstetrics and Gynecology, Medical College of Wisconsin, Milwaukee \\ ${ }^{3}$ Department of Pharmaceutics, University of Washington, Seattle, Washington, USA
}

\begin{abstract}
We report abnormal maternal laboratory parameters in twin-to-twin transfusion syndrome (TTTS) at mid-pregnancy. A retrospective chart review was undertaken of 109 patients with TTTS evaluated for placental laser surgery. Complete blood count (CBC), blood type and Rh factor, urine analysis and serum chemistry panel were obtained preoperatively, with the CBC and serum albumin repeated on the first postoperative day. The mean gestational age was $21.2 \pm 1.7$ weeks. Initial abnormal values included hematocrit $(32.1 \pm 3.0 \%)$, hemoglobin $(11.0 \pm 1.03 \mathrm{~g} / \mathrm{dl})$, serum magnesium $(1.71 \pm 0.17 \mathrm{mg} / \mathrm{dl})$, total protein $(6.08 \pm 0.55 \mathrm{~g} / \mathrm{dl})$ and albumin $(3.06 \pm 0.34 \mathrm{~g} / \mathrm{dl})$. Despite minimal blood loss and conservative fluid replacement mean hematocrit, hemogl obin, and al bumin were $27.3 \pm 2.74 \%, 9.3 \pm 0.94 \mathrm{~g} / \mathrm{dl}$ and $2.56 \pm 0.23 \mathrm{~g} / \mathrm{dl}$, respectively on postoperative day one. Weight gain $(8.0 \pm 5.5 \mathrm{lb}$.) and low urinary output were characteristic peri-operative events. Maternal hypoproteinemia and anemia occur in TTTS at mid-pregnancy. This may contribute independently to amniotic fluid production rates in the fetuses, and explain in part the maternal sensitivity to intravenous fluids in multiple pregnancy. Twin Research (2000) 3, 113-117.
\end{abstract}

Keywords: pregnancy complication, multiple gestation, monochorionic twins, twin-to-twin transfusion syndrome, polyhydramnios, hypoproteinemia, anemia, colloid osmotic pressure

\section{Introduction}

Twin-to-twin transfusion syndrome (TTTS) in previable gestations is associated with significant perinatal mortality and morbidity. ${ }^{1}$ The pathophysiology is linked to placental vascular anastomoses between monochorionic (MC) monozygous twins. ${ }^{2}$ However, TTTS is considered by some to be poorly understood $^{3}$ or enigmatic ${ }^{4}$ due to the lack of classic findings (hematocrit and weight differences) in the twins, ${ }^{5}$ the inability to document transfusion of blood in vivo between the twins in each case, ${ }^{3,6,7}$ the wide and unpredictable clinical fluctuations, ${ }^{8}$ and the difficulty relating clinical outcome directly to placental findings. ${ }^{9}$ Despite these concerns, the syndrome continues to affect approximately $15 \%$ of previable MC twins where high morbidity and mortality rates are seen both with and without therapeutic interventions.

Correspondence: Randall S Kuhlmann, MD, PhD, Department of Ob/Gyn - M.C.W., 9200 West Wisconsin Ave, Milwaukee, WI 53226 USA. Tel: 4142575560 ; Fax: 4142575686 ; E-mail: kuhlmann@mcw.edu
We have advocated fetoscopic laser separation of the twins' circulations in previable TTTS because it can address the underlying MC placental abnormalities and theoretically limit fetal consequences of prolonged twin transfusion physiology when compared with other therapies. Since the surgery is performed under general anesthesia for technical reasons described el sewhere,$^{10,11}$ routine preoperative laboratory tests are obtained. Our purpose is to report the maternal metabolic abnormalities seen in a cohort of previable TTTS cases, and discuss the possible relationship of these findings to pathologic fetal manifestations of TTTS, as well as some maternal morbidity associated with management of complications in multiple gestation.

\section{Methods}

Between October 1988 and September 1998, 109 patients with previable TTTS were referred to the investigators from centers throughout the United States and Canada for fetoscopic laser occlusion of the chorioangiopagous vessels. The evaluations and surgery were performed with IRB approval initially 
at the University of Utah (12 cases), then the Medical College of Wisconsin (56 cases) and the remainder (41 cases) at the University of Illinois at Chicago. The gestational age determinations and TTTS diagnoses were made by the referring centers using standard ultrasound criteria (single placenta, thin interfetal membrane septum, like-sex twins, polyhydramnios/ oligohydramnios sequence, and varying degrees of discordant growth with or without hydrops of one twin) and verified by repeat ultrasound scan preoperatively.

Preoperative laboratory assessment evolved over the 10 year period to include complete blood count (CBC), blood type and Rh factor, urinalysis, and a chemistry panel (12 to 22 components), all obtained on the morning of surgery. The CBC and serum albumin were repeated in the morning of the first postoperative day routinely starting with the 15 th and 60th cases, respectively. Patients were weighed on the morning of surgery and daily thereafter.

Initially, patients were maintained peri-operatively on volumes of intravenous fluid sufficient to maintain a normal urinary output. However, by the 13th case weight gain secondary to fluid retention was obvious. Thereafter, fluids were limited to $100 \mathrm{ml}$ crystalloid per hour prior to surgery and $125-150 \mathrm{ml}$ per hour postoperatively regardless of urinary output until bowel function returned. Indomethacin rectal suppositories limited to $50 \mathrm{mg}$ every $6 \mathrm{~h}$ for 1 day, then $25 \mathrm{mg}$ every $6 \mathrm{~h}$ for 2 days were used for prophylactic tocolysis.

Patients were discharged to their respective referral centers on the 4th to 8th postoperative day on regular diets along with nutritional supplements providing an additional $24-30 \mathrm{~g}$ of protein, 400-500 calories, and iron as tolerated per day.

\section{Results}

The mean maternal age was 32.5 years (range 17 to 43). Thirty-nine (36\%) were nulliparous. The mean gestational age at presentation was $21.2 \pm 1.7$ weeks (range 18 to 24.5). Of the origin 109 patients, nine were excluded from the laser surgery after admission for various technical or clinical issues.

With few exceptions normal values were obtained for serum el ectrolytes, bicarbonate, BUN, creatinine, uric acid, glucose, bilirubin, alkaline phosphatase AST, ALT, GOT, LDH, white blood cell and platelet counts, and the urine analysis (mean specific gravity $1.020 \pm 0.69$ ). Abnormal values were obtained preoperatively for hemoglobin, hematocrit, total protein, albumin, and magnesium (Table 1). Postoperatively the hemoglobin, hematocrit, and albumin fell further despite minimum blood loss $(\leq 100 \mathrm{ml})$ and conservative fluid replacement (Table 1).
Table 1 Abnormal maternal laboratory values in TTTS at midpregnancy

\begin{tabular}{lll}
\hline & & Range \\
\hline Preoperative baseline & & \\
Hemogl obin $(\mathrm{n}=109)$ & $11.0 \pm 1.03 \mathrm{~g} / \mathrm{dl}$ & $(7.5-13.5)$ \\
Hematocrit $(\mathrm{n}=109)$ & $32.1 \pm 3.0 \%$ & $(21-39.4)$ \\
Total Protein $(\mathrm{n}=96)$ & $6.08 \pm 0.55 \mathrm{~g} / \mathrm{dl}$ & $(4.8-7.7)$ \\
Albumin $(\mathrm{n}=97)$ & $3.06 \pm 0.34 \mathrm{~g} / \mathrm{dl}$ & $(1.9-3.7)$ \\
Magnesium $(\mathrm{n}=82)$ & $1.71 \pm 1.7 \mathrm{mg} / \mathrm{dl}$ & $(1.2-2.1)$ \\
& & \\
First postoperative day & & \\
Hemogl obin $(\mathrm{n}=95)$ & $9.3 \pm 0.94 \mathrm{~g} / \mathrm{dl}$ & $(7.4-11.5)$ \\
Hematocrit $(\mathrm{n}=95)$ & $27.3 \pm 2.74 \%$ & $(21-34)$ \\
Albumin $(\mathrm{n}=49)$ & $2.56 \pm 0.23 \mathrm{~g} / \mathrm{dl}$ & $(1.7-3.0)$ \\
\hline
\end{tabular}

Values are mean \pm S.D.; $n=$ number of patient values available.

The patients experienced a mean increase in weight of $8.0 \pm 5.5 \mathrm{lb}$. (range 1 to 23) during the postoperative period. However, by the 3rd to 5 th postoperative day all patients had begun a mobilization phase with daily weight loss until discharge from the hospital.

\section{Discussion}

Recent attempts to clarify both the diagnostic criteria and pathophysiology of TTTS in MC twins have underscored its complexity. ${ }^{12}$ The long established neonatal and prenatal ultrasonographic criteria, in addition to the pathophysiology of TTTS as originally proposed by Friedrich Schatz over 100 years ago $^{13}$ have all been questioned as investigators struggle to understand one of the most challenging problems in contemporary obstetrics. Clearly, there are factors which remain to be identified in the pathophysiologic process of TTTS.

Our post hoc observational study of severe TTTS cases at mid-pregnancy indicated significant maternal hypoproteinemia and anemia. Since no dysfunction was detected in any organ system included in the laboratory studies, we suspect these findings indicate inadequate to marginal intake of protein and calories, which in many cases was associated with the nausea and vomiting of early pregnancy, as a possible etiology. When combined with the increased demands of twin fetuses and some maternal manifestations of TTTS (eg, polyhydramnios may produce a uterine mass equivalent to a term gestation at only 20 weeks) nutritional status may be comprised rapidly. ${ }^{14}$

Maintenance of adequate nutrition and hydration in the mother was rarely addressed prior to referral, as were objective determinations of weight changes, since concerns for the fetuses seemed to overshadow maternal issues. However, weight increases from both the edema of maternal hypoproteinemia and 
fetal polyhydramnios might confound clinical determinations of malnutrition and dehydration in pregnancy where weight loss is an important parameter. Some patients reported limiting their intake of vital nutrients further when they experienced weight gain. The weight gain exceeded that which could be explained by the volumes of polyhydramnios al one.

Values of maternal serum protein and blood counts in normal pregnancy have been reported at gestational ages similar to our study group. ${ }^{15-17} \mathrm{At}$ mid-pregnancy the total protein, al bumin, hemoglobin and hematocrit range was $6.29-7.64 \mathrm{~g} / \mathrm{dl}$, $3.4-3.7 \mathrm{~g} / \mathrm{dl}, 11.5-12.5 \mathrm{~g} / \mathrm{dl}$ and $33-38 \%$, respectively. Although total protein (with albumin its principal component) and hemoglobin undergo a gradual decline during the first and second trimesters to a nadir at $26-34$ weeks gestation, ${ }^{17}$ levels are still within the normal range by mid gestation.

Based on these historical controls virtually all of our patients had laboratory evidence of hypoproteinemia and anemia. The low levels of serum magnesium seen at admission support the diagnosis of hypoproteinemia. ${ }^{18}$ We believe the levels of al bumin and blood counts obtained postoperatively to be more indicative of actual nutritional status, with preoperative values reflecting hemoconcentration from dehydration and hydrostatic-related movement of fluid into the interstitial space. These disorders of maternal nutrition may provide some insight into fetal manifestations of TTTS as well as some maternal morbidity associated with treating complications in multiple gestation.

The oligohydramnios of the donor twin notwithstanding, the predominant clinical manifestation in TTTS is the polyhydramnios of the recipient fetus. Without therapeutically reducing the recipients' amniotic fluid volume, TTTS in previable pregnancies is characterized by pregnancy loss as the uterine distention from progressive polyhydramnios in the recipient leads to premature labor or rupture of the membranes. The polyhydramnios is the result of urinary production rates greater than the 95th percentile for the gestational age. ${ }^{19,20}$ El evated umbilical cord atrial natriuretic peptide (ANP) found in most recipients mediates the increased fetal urine production and polyhydramnios. ${ }^{21,22}$

Neither the ANP produced secondary to volume overload nor the size of the transfusion (as demonstrated by the failure to show significant differences in hematocrit between the twins or abnormally elevated hematocrit levels in recipients in all cases) $)^{3,5}$ explain the origin of the increased blood volume responsible for the liters of excess amniotic fluid. We believe that in addition to any contributions from the donor, the source of this increased volume is passive absorption of water by the recipient from the mother as a consequence of the recipient's increased colloid osmotic pressure (COP) when compared with the decreased COP in the mother. The degree of polyhydramnios and classification of TTTS as mild or severe based on the volume of amniotic fluid observed and/or removed by amniocenteses may depend partly on worsening (or improving) maternal nutritional factors.

At mid-pregnancy a mean difference of $3.6 \mathrm{~g} / \mathrm{dl}$ in total serum proteins between the mother and fetus has been observed. ${ }^{23}$ Normal values reported for fetal albumin and total protein are given in Table $2 .{ }^{24,25}$ When coupled with values of fetal blood composition in TTTS (Table 2$)^{7,26}$ and compared with levels in normal pregnancy, there is evidence for our hypothesis that the severe polyhydramnios may be linked to increased COP in the recipient twin which enhances absorption of water from the mother. Asymmetric unidirectional flux of water across the placenta depends on hydrostatic and osmotic pressure differences in the fetal and maternal microcirculations. ${ }^{27}$ Although these pressures are

Table 2 Normal and abnormal mean fetal values from review of published studies

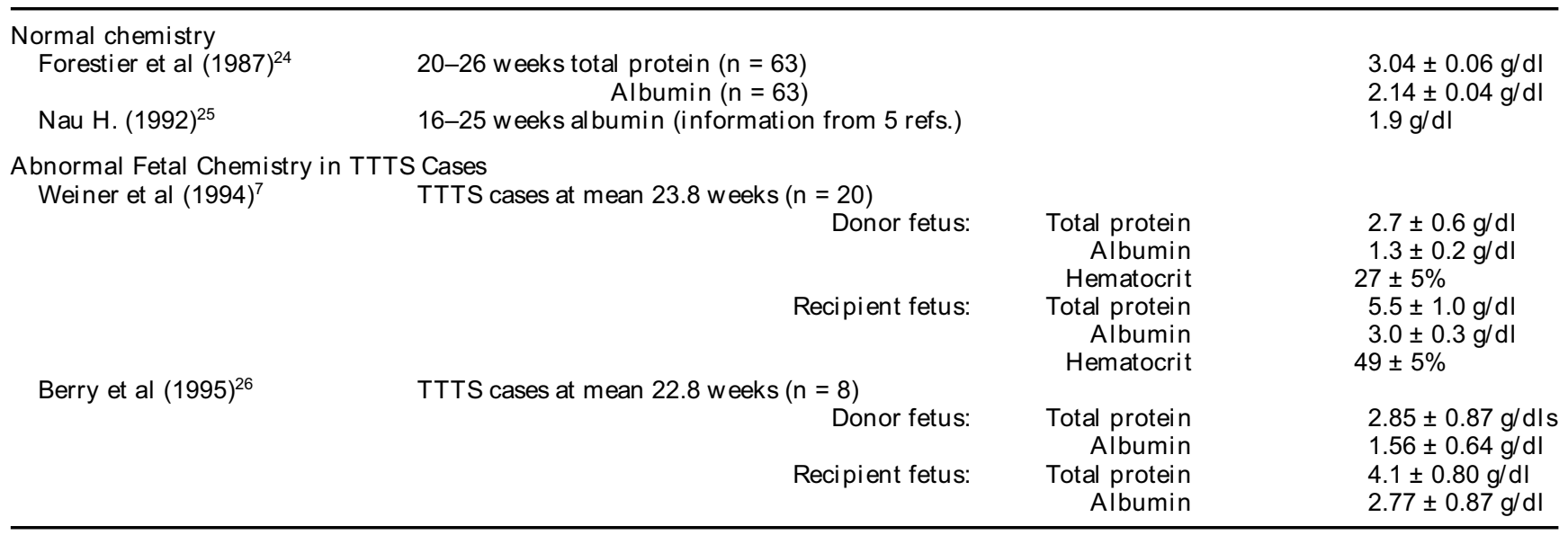


unknown in vivo, acutely increasing osmotic pressure of either maternal or fetal plasma by injecting hypertonic solutions has been shown to lead to a rapid net flux of water out of the fetus or mother respectively in experimental animals.

This relationship of serum proteins to TTTS findings was originally proposed by Kloosterman more than 35 years ago. ${ }^{28} \mathrm{He}$ perceived a flaw in the transfusion theory of Schatz and opined that the chain of events in TTTS fetuses must be understood not only from the point of view of the relationship between them but al so from that of their relationship with the mother. He attributed the hydramnios to minute rather than marked disturbances in hemodynamic equilibrium as proposed by Schatz, and the increased protein content of the 'transfusee' who absorbs fluid from the mother. However, maternal serum protein levels have never been measured simultaneously with fetal sampling in MC twins with or without TTTS.

Maternal COP normally declines to reach a nadir in the mid third trimester, ${ }^{17}$ and closely follows changes in both total protein and serum albumin values. ${ }^{15}$ Albumin is responsible for roughly $75 \%$ of plasma COP, although hydrostatic pressure, capillary permeability and lymphatics also determine whether fluid passes out of the intravascular space to cause edema of pregnancy or edma of pathologic (eg pulmonary) significance. Interest in hypoproteinemia and COP in pregnancy has focused primarily on intrapartum fluid management, postpartum edema, pregnancy induced hypertension, and tocolytic therapy. ${ }^{29}$ In multiple gestation, there appears to be a particular sensitivity to tocolytic therapy (approximately $20 \%$ of reported cases of pulmonary edema) characterized by an intolerance to intravenous fluids and $\beta$-mimetics. ${ }^{30}$

Specific pathophysiologic mechanisms for these complications in multiple gestation have not been identified. ${ }^{31}$ The abnormal metabolic parameters seen in our study population, the hypoproteinemia in particular, may be partially to blame. In a study of maternal oxygen desaturation events in women receiving intravenous magnesium therapy for premature labor, multiple gestation was the only one of 14 independent variables associated with low maternal oxygen saturation. ${ }^{32}$ Thirty-six percent of desaturation events occurred in multiple gestations (mean gestational age $27.4 \pm 2.6$ weeks). Although blood counts and serum proteins were not reported, the mean COP for the group (19.2 $\pm 2.3 \mathrm{~mm} \mathrm{Hg}$ ) was less than expected for this gestational age. ${ }^{17}$

Maternal nutritional status may have contributed to several cases of significant maternal morbidity associated with fetal surgery at mid-pregnancy. Demeyere et al reported severe edema, gastric paresis, vomiting and oliguria in the mother post- operatively at 22.5 weeks' gestation following fetoscopic placental laser surgery for TTTS. ${ }^{33}$ Laboratory studies indicated anemia and hyponatremia (serum protein was not reported), and despite hydration, blood transfusion and diuretics, termination of the pregnancy proved the only effective therapy. A similar experience occurred in a mother at 22 weeks' gestation also following fetoscopic laser surgery for TTTS (Saade G, personal communication, 1998). Despite conservative fluid management the patient developed pulmonary edema which required intubation (SpO2 of $78 \%$ ). Serum proteins were not measured, but a drop in the hematocrit obtained at admission from $29.4 \%$ to $20 \%$ contributed to the decision to terminate the pregnancy on the third postoperative day. No specific source of the respiratory failure or blood loss was ever determined. DiFederico et al reported a case of pulmonary edema in a 20 -year-old gravida3, para 1 woman following surgery to repair fetal congenital diaphragmatic hernia at 24.5 weeks. ${ }^{34}$ Hematocrit upon admission was $31 \%$ and fell to $22 \%$ intraoperatively necessitating transfusion of 3 units of packed RBCs. By the time the patient was intubated the net fluid excess was 6.1 liters, with central venous pressure at $11 \mathrm{~mm}$ Hg. In supporting their opinion that the etiology of the pulmonary edema was increased permeability rather than hydrostatic, they reported the mother's total plasma protein concentration as $3.95 \mathrm{~g} / \mathrm{dl}$ (similar to the protein content of the pulmonary edema fluid). The probability of maternal hypoproteinemia preoperatively was also supported by the serum magnesium at admission of $1.2 \mathrm{mg} / \mathrm{dl}$.

In light of the uncertainty expressed by these investigators, unrecognized maternal protein-calorie malnutrition could be etiologic and an unanticipated finding in these cases. Additionally, the degree of anemia may not have been evident at admission in these patients (as in ours) due to hemoconcentration from the effects of dehydration and low COP. The risks associated with the latter may be the false impression of surgery-related hemorrhage requiring transfusion, exploratory surgery or pregnancy termination.

This study relied on historical controls for comparison rather than recruiting ostensively a cohort of simultaneously sampled mothers and MC twin fetuses without TTTS. Fetal blood sampling was not undertaken in our TTTS cases because of ethical concerns for the additional risks involved, and the technical requirement for clear amniotic fluid with fetoscopic placental laser surgery. Nevertheless, the maternal metabolic abnormalities identified in our patients at mid-pregnancy may explain some TTTS fetal characteristics and maternal morbidity in multiple gestation. We encourage continued investigation and verification of these maternal factors that 
have been basically ignored in TTTS and fetal therapy.

\section{Acknowledgements}

This research was supported in part by the National Institutes of Health General Clinical Research Center grants No. M01 RR-00064 and No.M01 RR-00058, and the Twin to Twin Transfusion Syndrome Foundation, Inc.

\section{References}

1 Lopriore E, Vandenbussche FP, Tiersma ES, de Beaufort AJ, de Leeuw JP: Twin-to-twin transfusion syndrome: New perspectives. JPediatr 1995; 127: 675-680.

2 Benirschke K, Kim CK: Multiple pregnancy. N Engl J Med 1973; 288: 1276-1284.

3 Fisk NM, Borrell A, Hubinont C, Tannirandorn Y, Nicolini U, Rodeck $\mathrm{CH}$ : Fetofetal transfusion syndrome: Do the neonatal criteria apply in utero? Arch Dis Child 1990; 65: 657-661.

4 Danskin FH, Neilson JP: Twin-to-twin transfusion syndrome: What are appropriate diagnostic criteria? Am JObstet Gynecol 1989; 161: 365-369.

5 Carroll SG, McLennan A, Maxwell DJ: Fetal hemoglobin changes in the twin oligohydramnios-polyhydramnios sequence. Ultrasound Obstet Gynecol 1997; 9: 398-402.

6 Bruner JP, Rosemond RL: Twin-to-twin transfusion syndrome: A subset of the twin oligohydramnios-polyhydramnios sequence. Am J Obstet Gynecol 1993; 169: 925-930.

7 Weiner CP, Ludomirski A: Diagnosis, pathophysiology, and treatment of chronic twin-to-twin transfusion syndrome. Fetal Diag Ther 1994; 9: 283-290.

8 Bromley B, Frigoletto FD, Estroff JA, Benacerraf BR: The natural history of oligohydramnios/polyhydramnios sequence in monochorionic diamnionic twins. Ultrasound Obstet Gynecol 1992; 2: 317-320.

9 Bendon RW: Twin transfusion: Pathological studies of the monochorionic placenta in liveborn twins and of the perinatal autopsy in monochorionic twin pairs. Pediatric Path Lab Med 1995; 15: 363-376.

10 De Lia JE, Kuhlmann RS, Harstad TW, Cruikshank DP: Fetoscopic laser ablation of placental vessels to treat severe twin-twin transfusion syndrome. Am J Obstet Gynecol 1995; 172: 1202-1211.

11 De Lia JE: Surgery of the placenta and umbilical cord. Clin Obstet Gynecol 1996; 39(3): 607-625.

12 Cincotta RB, Fisk NM: Current thoughts on twin-twin transfusion syndrome. Clin Obstet Gynecol 1997; 40(2): 290-302.

13 Schatz F: Eine besondere Art von einseitiger Polyhydramnie mit anderseitiger Oligohydramnie bei eineiigen Zwillingen. Arch Gynaekol 1882; 19: 329-369.

14 Erick M: Nausea and vomiting in pregnancy. ACOG Clin Rev 1997; 2(3): 1-16.
15 Robertson EG, Cheyne GA: Plasma biochemistry in relation to oedema of pregnancy. J Obstet Gynaecol Brit Comm 1972; 79: 769-776.

16 Pitkin RM, Reynolds WA, Williams GA, Hargis GK: Cal cium metabolism in normal pregnancy: A longitudinal study. Am J Obstet Gynecol 1979; 133: 781-787.

17 Wu PY, Udani V, Chan L, Miller FC, Henneman CE: Colloid osmotic pressure: Variations in normal pregnancy. JPerinatal Med 1983; 11: 193-199.

$18 \mathrm{Kroll} \mathrm{MH}$, Elin RJ. Relationships between magnesium and protein concentration in serum. Clin Chem 1985; 31: 244-246.

19 Kirshon B: Fetal urine output in hydramnios. Obstet Gynecol 1989; 73: 240-242.

20 Rosen DJ, Rabinowitz R, Beyth Y, Fejgin MD, Nicolaides KH: Fetal urine production in normal twins and in twins with acute polyhydramnios. Fetal Diag Ther 1990; 5: 57-60.

21 Nageotte MP, Hurwitz SR, Kaupke CJ, Vazi ri ND, Pandian MR: Atriopeptin in the twin transfusion syndrome. Obstet Gynecol 1989; 73: 867-870.

22 Breckwoldt M: Pathophysiology of polyhydramnios in twin transfusion syndrome. Fetal Diagn Ther 1992; 7: 87-92.

23 Nava S, Bocconi L, Zuliani G, Kustermann A, Nicolini U: Aspects of fetal physiology from 18 to 37 weeks' gestation as assessed by blood sampling. Obstet Gynecol 1996; 87: 975-980.

24 Forestier F, Daffos F, Martine R, Bruneau M, Trivin F: Blood chemistry of normal human fetuses at midtrimester of pregnancy. Pediatr Res 1987; 21: 579-583.

$25 \mathrm{Nau} \mathrm{H}$ : Structural properties regulating placental drug transfer. In: Polin RA, Fox WW (eds). Fetal and Neonatal Physiology. W.B. Saunders: Philadel phia, 1992, pp 130-141.

26 Berry SM, Puder KS, Bottoms SF, Uckele JE, Romero R, Cotton DB: Comparison of intrauterine hematologic and biochemical values between twin pairs with and without stuck twin syndrome. Am J Obstet Gynecol 1995; 172: 1403-1410.

27 Sibley CP, Boyd RD: Mechanisms of transfer across the human placenta. In: Polin RA, Fox WW (eds). Fetal and Neonatal Physiology. W.B. Saunders: Philadel phia, 1992, pp 62-74.

28 Kloosterman GJ. The third circulation in identical twins. Ned T Verlosk 1963; 63: 395-412.

29 Cotton DB: Colloid oncotic pressure. In: Clark SL, Cotton DB, Hankins GD, Phel an JP(eds). Critical Care Obstetrics, 3rd edn. Blackwell Science: Cambridge, 1997; pp 55-75.

30 Grospietsch G, Kuhn W: Effects of betamimetics on maternal physiology. In: Fuchs F, Fuchs AR, Stubblefield PG (eds). Preterm Birth: Causes, Prevention, Management. McGrawHill: New York City, 1993, pp 279-307.

31 Blickstein I: Maternal mortality in twin gestations. J Reprod Med 1997; 42: 680-684.

32 Thorp JA, Neimark M, Poskin M: Maternal oxygen desaturation with intravenous magnesium therapy. Obstet Gynecol 1997; 89: 963-966.

33 Demeyere T, Van Schoubroeck D, Deprest J, Spitz B: Maternal hydrops after laser surgery in twin-to-twin transfusion syndrome. Fetal Diag Ther 1998; 13(Suppl): 124.

34 DiFederico EM, Harrison M, Matthay MA: Pulmonary edema in a woman following fetal surgery. Chest 1996; 109: $1114-1117$. 